\title{
Educação Especial: por uma escola para todos
}

\author{
Luciana Varela Rocha Mathias ${ }^{1}$;Maria Cristina Oliveira Lustosa ${ }^{2}$
}

Resumo: Através de leituras e análises de trabalhos científicos, pretendeu-se expor relevante ponto de vista sobre o tema abordado. Percebe-se que nas últimas décadas o tema educação especial e a inclusão no ambiente educacional tem sido muito refletido e debatido. Entretanto, percebe-se que em sua trajetória houve significativas transformações tanto sociais como também pedagógicas. Diante disso, esse estudo tem como temática central o desafio da inclusão de alunos com necessidades especiais na escola e sua integração com a comunidade escolar. Mais especificamente, pretendeu-se analisar a educação especial, apontando questões ligadas a essa inclusão educacional. A metodologia constitui por meio de pesquisa bibliográfica, através de análises de estudos acerca do tema. Contudo, há a necessidade de um conjunto de ações aliada a um olhar diferenciado no processo de ensino e aprendizagem com uma aceitação de uma educação inclusiva por parte de toda comunidade escolar, construindo assim, o conhecimento e uma efetiva socialização..

Palavras-chave: Educação Especial. Educação Inclusiva. Ambiente Escolar.

\section{Special Education: for a School for everyone}

\begin{abstract}
Through scientific papers readings and analysis, we sought to expose relevant point of view about the topic. It is noticed that in recent decades the subject special education and inclusion in the educational environment has been much discussed and reflected. However, one can see that in his career there were significant both social changes as well as teaching. Therefore, this study has as its central theme the challenge of inclusion of students with special needs in school and their integration with the school community. More specifically, the aim was to analyze the special education, pointing to issues that educational inclusion. The methodology is by means of literature through analysis of studies on the subject. However, there is a need for a set of actions combined with a different look in the teaching and learning process with an acceptance of an inclusive education for all school community, thus building, knowledge and effective socialization.
\end{abstract}

Keywords: Special Education. Inclusive Education. School environment.

\footnotetext{
${ }^{1}$ Mestranda em Educação, Anne Sullivan University. Email: luvoroma@ bol.com.br;

${ }^{2}$ Graduada em Letras - Língua Portuguesa pela Universidade Regional do Cariri. Mestranda em Ciências da Educação pela Anne Sullivan University. Atualmente é coordenadora pedagógica e professora - Colégio Natanael Cortez, Brasil.
} 
Id on Line Revista Multidisciplinar e de Psicologia

Id on Line Multidisciplinary and Psycology Journal

\section{Introdução}

Portadores de necessidades especiais são indivíduos com alterações físicas, sensoriais e cognitivas, em que são incluídos em uma categoria denominada deficiente (ALVES et al, 2010).

E este portador de alguma deficiência tem sido inserido no ensino regular, na modalidade de educação especial, em que deve ter direito a uma educação formal, algo que antes lhe era negado. Segundo Mrech (2009) entende-se por educação inclusiva o processo que inclui os portadores de necessidades especiais na rede de ensino regular.

Se pensarmos no processo histórico que foi construído em torno de pessoas com deficiência, vemos que as discursões e debates em torno desse tema avançaram bastante, mas ainda há muito que construir e precisa-se de várias informações sobre a temática, como também respeito e amor ao próximo.

O autor Garcia (2015) relata que anteriormente as pessoas com deficiências eram sacrificadas e/ou marginalizadas, crianças eram mortas logo após o nascimento se percebessem alguma "diferença". Incapacidades físicas e malformações congênitas eram consideradas como castigo de Deus. E ainda, pessoas com deficiência estavam completamente integradas ao contexto da pobreza e marginalidade, como por exemplo, os cegos, surdos, deficientes mentais e físicos eram explorados para serviços simples e humilhantes.

As pessoas portadoras de alguma deficiência eram também mantidas escondidas, sem nenhum convívio social ou educação formal, os que por ventura se apresentavam a sociedade, eram a procura de resultados que ajudassem a melhorar o estado da mobilidade física e motora do indivíduo. (MENDONÇA, 2015). Mas a partir do momento que a educação especial passou a ser priorizada, a pessoa com alguma deficiência deixou de ser vista de forma isolada e passou a ser parte integrante de uma educação formal.

Art. 58. "Entende-se por educação especial, para efeitos desta Lei, a modalidade de educação escolar, oferecida preferencialmente na rede regular de ensino, para educandos portadores de necessidades especiais". LDBN nº 9.394/96.

Mas para colocar a Educação especial em prática requer condições de acesso e permanência na escola como um dos princípios para o ensino e aprendizagem. E essa inclusão 
Id on Line Revista Multidisciplinar e de Psicologia

Id on Line Multidisciplinary and Psycology Journal

na escola condensa-se na socialização e aprendizagem (VIEIRA, 2015). Aprendizagem entre outros aspectos esta ligada a um desempenho profissional e ambiente qualificado para atender as necessidades desses alunos. Incluir é acolher, e reconhecer o outro como parte integrante é necessária ao processo escolar.

Diante do exposto, surgiram questões norteadoras para a presente pesquisa: Até que ponto é um desafio para a escola a inclusão dos alunos especiais? A educação especial é parte integrante da comunidade escolar ou apenas ocupa o ambiente escolar para que seja cumprida a lei?

Sendo assim objetivou-se analisar as perspectivas de uma educação especial e uma educação para todos, detectando como se deu a necessidade de incluir no mesmo ambiente escolar, alunos especiais e alunos "normais" e identificando o que caracteriza uma escola para todos e de que forma todos participam dessa educação nos estudos referentes a esta educação.

Diante disso, justifica-se a relevância desse estudo a necessidade de conhecer de que forma está ocorrendo o processo de inclusão das pessoas com alguma deficiência nas escolas e, como se encontra reflexões e inquietações a respeito da temática.

\section{Metodologia}

Realizou-se no período de Março e Abril de 2015 um levantamento bibliográfico, em que se buscou identificar e analisar os artigos relacionados à educação especial na perspectiva de uma escola para todos.

O estudo foi realizado através de pesquisa bibliográfica, considerando a relevância ao tema, buscando conhecer ideias e o olhar de diferentes autores sobre assunto em questão. A revisão bibliográfica, segundo Santos (2012), visa demonstrar o estágio atual da contribuição acadêmica em torno de um determinado assunto, proporcionando uma visão abrangente de pesquisas e contribuições anteriores, conduzindo ao ponto necessário para investigações futuras e desenvolvimento de estudos posteriores.

Para a composição e seleção dos artigos, adotaram-se os seguintes critérios de inclusão: o ano de publicação, em que foram consideradas as pesquisas publicadas entre os anos de 2010 
Id on Line Revista Multidisciplinar e de Psicologia

Id on Line Multidisciplinary and Psycology Journal

a 2015, em periódicos das bases de dados investigadas. Como também pesquisas realizadas no Brasil com textos em português, que estejam disponíveis em texto completo, e, por fim, artigos relacionados diretamente ao tema. E como critérios de exclusão: artigos que traziam em seus resumos aspectos diferentes aos objetivos deste levantamento.

Os descritores utilizados para pesquisa dos artigos foram "Educação Especial", "Educação Inclusiva" e "Ambiente Escolar" no portal de periódicos da CAPES e a base de dados da Biblioteca Digital Brasileira de Teses e Dissertações (BDTD). A busca foi realizada pelo acesso on-line e, utilizando os critérios acima citados, a amostra final desta revisão bibliográfica foi constituída de 11 artigos.

A apresentação dos resultados e discussão dos dados obtidos foi feita de forma descritiva a fim de fornecer subsídios para uma maior compreensão do tema.

\section{Resultados e Discussões}

De acordo com a realização do levantamento dos artigos relacionados à temática pesquisada, a maioria relatou a preocupação dos autores com a necessidade em falar e debater mais sobre o assunto.

Muitos dissertaram sobre Educação Especial e sua Inclusão na Escola, direito adquirido, despreparo de instituições, como também a formação de professores para atender essa modalidade no ensino regular e que é necessário muito mais que leis já existentes, e/ou muitas vezes mal cumpridas, e/ou mal entendidas, e/ou ignoradas. E ainda relataram os benefícios de uma educação inclusiva efetiva.

O processo de inclusão é para todos e a interação uns com os outros desenvolvendo habilidades educativas e sociais é primordial para o sucesso da inclusão. Mas o que se identifica é um despreparo, deixando a desejar em vários aspectos o processo de ensino e aprendizagem. Há necessidade de um conjunto de ações aliada a um olhar diferenciado no processo de ensino e aprendizagem que realmente inclua e uma aceitação e participação por parte de toda comunidade escolar, somente assim poderá trabalhar educação nos seus sentidos amplos e restritos. 
Id on Line Revista Multidisciplinar e de Psicologia

Id on Line Multidisciplinary and Psycology Journal

\section{Inclusão na Escola}

A inclusão efetivamente é aquela que trabalha no que se baseia principalmente, entre outros aspectos, nos princípios e valores éticos, na projeção dos ideais de cidadania e justiça, e ainda conceitua a educação inclusiva através da interação, socialização e a própria construção do conhecimento (VIEIRA, 2015).

Sendo assim o conceito de inclusão no âmbito escolar é uma modalidade de ensino em que toda comunidade deve estar envolvida, fazendo parte da mesma construção de conhecimento e visando nesse processo de ensino e aprendizagem, uma interação e uma socialização na construção de uma escola para todos.

\section{Direito Adquirido}

A escola reflete uma educação imposta pela sociedade, ela trabalha para formar o cidadão que a sociedade exige e almeja, com um conjunto de medidas que determina a construção do conhecimento e do indivíduo. O portador de deficiência adquiriu direitos ao longo da história e, portanto, tem as mesmas oportunidades de alunos "normais" de receber uma educação formal , que antes eles não tinham, sendo construída assim, uma escola para todos que de forma efetiva forme um cidadão exigido para uma sociedade justa e includente.

Como vemos pelo comentário de Prado (2001) sobre a escola carregar uma bagagem de cultura e de saberes que atendiam às necessidades de uma determinada época e clientela. Porém há uma diferença reconhecida pelo processo histórico, no tratamento dado a criança com algum tipo de deficiência. Se antes o portador de deficiência era eliminado da sociedade, hoje ele tem seu direito adquirido por lei, que o coloca com os mesmos direitos das demais crianças, tendo a possibilidade de aprender em conjunto em uma mesma instituição de ensino. 
Id on Line Revista Multidisciplinar e de Psicologia

Id on Line Multidisciplinary and Psycology Journal

\section{Despreparo das Instituições}

Para haver inclusão é preciso uma nova concepção de escola e aluno, como também uma nova compreensão sobre ensinar e aprender, somente leis e decretos não garante que as escolas regulares aceitem os alunos com necessidades especiais. Somente a presença física do aluno deficiente na sala de aula não é garantia de uma inclusão. A escola deve estar preparada para trabalhar com os alunos, independente das diferenças ou características individuais deles (FERNANDES, 2011).

Enquanto LINO (2006) reforça que a educação inclusiva não se efetivará simplesmente por decreto, será necessário ir mais além, requer uma avaliação das reais condições que possibilitam a inclusão gradativa e sistematicamente planejada, tendo em vista a possibilidade de ruptura total com o sistema educacional e a conquista de uma sociedade solidária que respeite, valorize e conviva com as diversidades.

Há a necessidade de uma nova concepção de escola, de aprender e ensinar e de sociedade para mudar realmente conceitos e valores já existentes em nosso meio. A mudança se faz necessária para receber realmente indivíduos portadores de alguma deficiência nas instituições de ensino e na sociedade de forma justa e igualitária.

Para LOPES (2000) a ideia de integração e inclusão de pessoas com necessidades especiais é um processo que requer, para sua consolidação, a concorrência de múltiplos esforços e a participação de todos os segmentos da sociedade de forma que se crie uma consciência social.

Somente os direitos adquiridos ao longo dos anos não garante uma educação inclusiva e de qualidade para os portadores de deficiência. Há uma concordância de ideias quando relatam o despreparo das instituições de ensino. (FERNANDES, 2011; LINO,2006; LOPES,2000).

\section{Formação do Professor}

Em relação à formação de professores, os cursos precisam de um direcionamento teórico-prático, com currículos e aulas teóricas, estágios supervisionados com espaços para 
Id on Line Revista Multidisciplinar e de Psicologia

Id on Line Multidisciplinary and Psycology Journal

discursões e reflexões teóricas sobre sua prática, como também material específico de uso do aluno com deficiência, uma equipe de professores que tenham além do conhecimento teórico, experiência na habilitação, pois muitas vezes estes são dotados de formação teórica e titulação, mas sem vivência prática (LINO, 2006).

Neste sentido a experiência de trabalho não funciona sem uma fundamentação teórica e vice e versa, sendo necessário para formar bem os professores para que sejam realmente educadores.

Para ensinar o princípio da socialização Lima (2014) diz que, é preciso considerar a importância da formação continuada, que é a base para lidar com as situações inusitadas na escola. As políticas públicas precisam, pois, criar condições de organização de um trabalho docente que possibilite a todos os docentes, simultaneamente, a participação em cursos que qualifiquem a sua prática, bem como o exercício de uma prática pedagógica qualificada que promova a aprendizagem dos alunos.

Porém é relatado por Facco (2007) que na formação deste professor é necessário trabalhar a questão da integração dessas crianças com as demais. As políticas públicas devem ser repensadas, visando facilitar, a cada dia, a execução desse processo. A visão multidisciplinar tem que se fazer presente na formação desses docentes, com o intuito de facilitar cada vez mais esta forma de trabalho, bem como fornecer subsídios aos professores.

Lino (2006), Lima (2014) e Facco (2007) concordam que é necessário rever a formação de professores que irão trabalhar com pessoas com alguma deficiência, uma teoria aliada a prática com uma ação-reflexão-ação fazendo parte do processo.

Tanto as universidades com a renovação de seus currículos ofertados e direcionados para uma teoria e prática com uma visão multidisciplinar, como também as politicas públicas orientando para uma formação adequada aos professores, o trabalho pedagógico deve rever suas ações no que diz respeito a inclusão e o efetivo cumprimento das leis que garantem um ensino e uma aprendizagem de qualidade e igualdade.

Para Menezes (2010) a busca de um olhar critico sobre os questionamentos dos professores a respeito da educação dos alunos com necessidades educacionais especiais, é onde se aloja nossa inquietação e reflexão sobre o lidar com os alunos "diferentes". Limitações pessoais como insegurança e preconceito, falta de vivência social pode se constituir como barreiras e acreditamos que a formação se mostra como ponto fundamental neste cenário. 
Id on Line Revista Multidisciplinar e de Psicologia

Id on Line Multidisciplinary and Psycology Journal

A autora anteriormente citada ainda comunga da mesma opinião dos demais quanto a repensar a formação dos educadores que irão trabalhar com alunos com necessidades especiais. Mas também ela aborda um tema que é muito importante e pouco relatado que é a insegurança, a limitação e o conceito pré-concebido que existe, seja na comunidade escolar e/ou na própria sociedade.

Pensando assim, a formação dos educadores não deve ser somente teórica e prática, mas também e essencialmente psicológica, trabalhar os sentimentos, medos e anseios que envolvem esse profissional na sua prática docente.

\section{Benefícios da Inclusão}

Para que a educação inclusiva tenha capacidade de municiar todo e qualquer indivíduo, com o mínimo indispensável para sua vida em sociedade, Menezes (2010) diz que se precisa promover a aprendizagem e favorecer as potencialidades de todos os alunos, levando em consideração as dificuldades e particularidades que estes possam apresentar.

E assim a inclusão é um movimento com apenas um interesse construir uma sociedade para todos. Mesmo sendo muito recente o movimento sobre inclusão, o conhecimento das diferenças em cada criança incluída torna fundamental esse processo de inclusão (PRADO, 2001).

O ideal para uma educação inclusiva efetiva é viver a diferença, buscando o direito a educação, construindo um saber de forma coletiva e vivendo em sociedade. Como consolidado por Menezes (2010) e Prado (2001) em que discorrem sobre o processo de inclusão que é para todos, pois é um preparo para a vida, para o mundo e o mercado de trabalho é a interação uns com os outros desenvolvendo habilidades educativas e sociais. 
Id on Line Revista Multidisciplinar e de Psicologia

Id on Line Multidisciplinary and Psycology Journal

\section{Considerações Finais}

Os trabalhos estudados apontam que há necessidade de uma mudança no processo de inclusão de alunos com necessidades especiais no ensino regular. A questão da formação de professores como um novo educador para um novo ensino e aprendizagem, que perpassa pela formação e experiência da diferença.

Como também a politica nacional de educação especial não garante o direito de uma educação inclusiva e uma escola para todos. Assegurar de fato o acesso desses alunos ao ensino regular é o almejado.

Garantir matrícula no ensino regular não é sinônimo de inclusão, como também, construir o PPP (Projeto Político Pedagógico) da escola incluindo atividades com essa modalidade de ensino, uma estrutura física e materiais pedagógicos e didáticos, mesmo assim não é garantia de alunos especiais inclusos. Mas um conjunto de todas essas ações aliada a um olhar diferenciado no processo de ensino e aprendizagem e uma aceitação de toda comunidade escolar construindo uma efetiva socialização.

. O processo de inclusão é para todos e a interação uns com os outros desenvolvendo habilidades educativas e sociais é primordial para o sucesso da inclusão. Mas o que se identifica nas escolas é um despreparo e em grande parte das instituições escolares que não se adaptaram a essa realidade e continua oferecendo um ensino capenga deixando a desejar em vários aspectos o processo de ensino e aprendizagem dessa modalidade de ensino.

Educação é uma orientação e decisão, é um estado de fora para dentro, dando um caminho a ser seguido e alcançado. É também um estado de dentro para fora, um potencial, uma capacidade de desenvolver alguma coisa que modifique a sua atual realidade, o extrair de dentro um conhecimento e aprimorá-lo de forma efetiva e verdadeira, somente assim pode-se trabalhar educação nos seus sentidos amplos e restritos. 
Id on Line Revista Multidisciplinar e de Psicologia

Id on Line Multidisciplinary and Psycology Journal

\section{Referências}

BAMPI, Luciana Neves da Silva; GUILHEM, Dirce; ALVES, Elioenai Dornelles. Modelo social:: uma nova abordagem para o tema deficiência. Disponível em:

<http://www.scielo.br/pdf/rlae/v18n4/pt_22.pdf>. Acesso em: 23 mar. 2015.

FACCO, Marília Alves, Educação Inclusiva e Atividade Docente: Um Caminho Difícil. Disponível em: <http://livros01.livrosgratis.com.br/cp032324.pdf>. Acesso em: 03 abr. 2015.

FERNANDES, Lorena Barolo; SCHLESENER, Anita; MOSQUERA, Carlos. BREVE HISTÓRICO DA DEFICIÊNCIA E SEUS PARADIGMAS. Disponível em:

<http://www.fap.pr.gov.br/arquivos/File/extensao/Arquivos2011/NEPIM/NEPIM_Volume_0 2/Art08_NEPIM_Vol02_BreveHistoricoDeficiencia.pdf〉. Acesso em: 27 mar. 2015.

GARCIA, Vinícius Gaspar. As pessoas com deficiência na história do mundo. Disponível em: <http://www.bengalalegal.com/pcd-mundial>. Acesso em: 26 mar. 2015.

LIMA, Eunice Tavares Silveira. Política de inclusão [manuscrito] : um estudo na rede pública de educação em Jataí-Goiás / Eunice Tavares Silveira Lima. Goiânia, 2014.

LINO, Débora Maria de Paula. O professor de Educação Especial Frente às Políticas Públicas de Educação Inclusiva: Um Estudo sobre Identidade. Disponível em: <http://www.sapientia.pucsp.br/tde_busca/arquivo.php?codArquivo=4405>. Acesso em: 27 mar. 2015.

LOPES, Renato Paula Vieira; MARQUEZAN, Reinoldo. O ENVOLVIMENTO DA FAMÍLIA NO PROCESSO DE INTEGRAÇÃO/INCLUSÃO DO ALUNO COM NECESSIDADES ESPECIAIS. Disponível em: http://cascavel.ufsm.br/revistas/ojs->. Acesso em 27 mar. 2015

MENDONÇA, Thais de. Acesso do portador de necessidade especial. Disponível em:<http://unesdoc.unesco.org/images/0015/001585/158524por.pdf $>$. Acesso em: 22 mar. 2015.

MENEZES, Maria Aparecida de. Formação de Professores de Alunos com Necessidades Educacionais Especiais no Ensino Regular. Disponível em:

$<$ http://www.educadores.diaadia.pr.gov.br/arquivos/File/2010/artigos_teses/2010/Pedagogia/t form_prof_alunos_neces_esp.pdf >. Acesso em: 01 abr. 2015.

MRECH, Leny Magalhães. O que é Educação Inclusiva? Disponível em: <http://www.luzimarteixeira.com.br/wp-content/uploads/2010/10/1-o-que-e-educacaoinclusiva.pdf >. Acesso em: 22 mar. 2015. 
PRADO, Ana Maria C. C. do; MAROSTEGA, Vera Lucia. A Inclusão do Portador de Necessidades Especiais em Âmbito Social e Escolar. Disponível em:

<http://coralx.ufsm.br/revce/ceesp/2001/01/r1.htm>. Acesso em: 27 mar. 2015.

REPUBLICA, Presidência da. Lei 939496. Disponível em:

<http://www.planalto.gov.br/ccivil_03/leis/19394.htm>. Acesso em: 21 mar. 2015.

VIEIRA, Givanilda Marcia. Educação inclusiva no brasil: do contexto histórico à contemporaneidade. Disponível em:

$<$ http://www.mpba.mp.br/atuacao/ceduc/educacaoinclusiva/artigos/EDUCACAO_INCLUSIV A_NO_BRASIL.pdf $>$. Acesso em: 21 mar.2015.

\section{Como citar este artigo (Formato ABNT):}

MATIAS, L.V.R.; LUSTOSA, M.C.O. Educação Especial: por uma escola para todos. Id on Line Revista Multidisciplinar e de Psicologia, Janeiro de 2017, vol.10, n.33, Supl 2. p. 271-281. ISSN: 1981-1179.

Recebido: 16/01/2017

Aceito: $19 / 01 / 2017$ 